\title{
Meningiomas: criteria for modern surgical indications
}

\author{
Paolo Cappabianca, Elena d’Avella, Luigi Maria Cavallo, Domenico Solari
}

Department of Neurosciences and Reproductive and Odontostomatological Sciences, Division of Neurosurgery, University of Napoli "Federico II", Naples 80131, Italy.

Correspondence to: Dr. Elena d'Avella, Department of Neurosciences and Reproductive and Odontostomatological Sciences, Division of Neurosurgery, University of Napoli “Federico II”, Via Pansini, 5, Naples 80131, Italy. E-mail: elenadavella@gmail.com

How to cite this article: Cappabianca P, d'Avella E, Cavallo LM, Solari D. Meningiomas: criteria for modern surgical indications. Mini-invasive Surg 2020;4:83. http://dx.doi.org/10.20517/2574-1225.2020.67

Received: 30 Jun 2020 First Decision: 4 Aug 2020 Revised: 4 Aug 2020 Accepted: 5 Aug 2020 Published: 13 Nov 2020

Academic Editor: Oreste de Divitiis Copy Editor: Cai-Hong Wang Production Editor: Jing Yu

\begin{abstract}
The contemporary management of meningiomas is the result of the continuous evolution of neurosurgical techniques, along with the refinement of dedicated instrumentations. Above all, it is the magnification of the surgical view, thanks to the microscope and the endoscope, and their advancements, which allowed the improvement of surgical outcomes, in terms of both extent of resection and morbidity rates. Because of the benign nature of the vast majority of meningiomas, complete tumor resection is curative, and it is the goldstandard treatment. However, in the case of high risk of surgical morbidity, a less aggressive surgical treatment may be justified, also upon tailored analysis of the meningiomas' biological behavior and the improvements in postoperative strategies. The endoscopic technique plays a role, as a unique visualization tool or in combination with the microscope, in granting so-called maximum allowed resection. Considering the above, the most challenging task confronting modern meningioma surgery remains the selection of the most appropriate surgical approach, the latter greatly depending on location, anatomic tumor features, and relationships with critical neurovascular structures. Herein, we present a cogent analysis of the modern multifaceted indications for the endoscopic treatment of meningiomas, with a glimpse into the adjacent fields.
\end{abstract}

Keywords: Meningiomas, endoscopic-assistance, endoscopic endonasal, postoperative treatments 


\section{INTRODUCTION}

Meningiomas are the most common benign intracranial tumors, with an incidence rate reaching up to $98 / 100,000$ individuals per year ${ }^{[1-4]}$. They are much more prevalent than spinal meningiomas that account only for $1.2 \%-12.7 \%$ of all meningiomas and $25 \%$ of all spinal tumors. Meningiomas originate from arachnoidal (meningothelial) cells and, upon histological grading, the World Health Organization (WHO) recognizes benign grade I tumors (75\%), atypical grade II meningiomas (20\%-35\%), and the malignant or anaplastic grade III subset $(1 \%-3 \%)^{[5]}$. The primary dural attachment site is another criterion for meningiomas classification. Intracranial meningiomas arise most commonly at the convexity (34.7\%), often adjacent to the venous sinuses $(22.3 \%)$, as compared to skull base tumors. Among infratentorial meningiomas, the majority (50\%) are at the cerebellar convexity. Spinal meningiomas are most frequently located at the thoracic spine (67\%-84\%), followed by the cervical spine (14\%-27\%) and the lumbar spine (2\%-14\%). Initially proposed by Harvey Cushing and Louise Eisenhardt, the classification of meningiomas based on primary dural attachment helps describe the natural history, including the development of signs and symptoms, and the plan for an appropriate management strategy ${ }^{[6]}$. Clinical presentation mostly depends on tumor size and location ${ }^{[1,2,4]}$; tumors impinging the eloquent cortex often present with seizures, whereas skull base lesions more often present with cranial nerve deficits. Being a space-occupying lesion, all meningiomas can of course present with raised intracranial pressure. Spinal meningiomas may present with signs of acute or chronic spinal cord compression, neurologic dysfunction, and progressive myelopathy, according to the location. Seldom, meningiomas are found accidentally and without related symptoms, in ca. $3 \%$ of the population ${ }^{[7]}$. Contrast enhanced MRI of the brain diagnoses and defines the details of meningioma; however, prediction of different histological subtypes of meningiomas is still not possible by conventional or advanced (diffusion-weighted imaging, perfusion imaging, and magnetic resonance spectroscopy) imaging techniques ${ }^{[8,9]}$. Recently, radiomics-based machine-learning methods have rapidly become a promising technique for analyzing medical imaging in clinical oncology. By analyzing the spectral distribution of image pixels, valuable texture features of the meningioma, such as tumor cellularity, degenerative changes, and neovascularization, can be extracted and correlated to prognostic score ${ }^{[10,11]}$. Continuous advances in radiomics will provide more information in regard to the tumor clinical behavior before surgery, with the potential impact of defining lesion clinical management.

Intracranial meningioma surgery with the goal of a radical resection has historically been performed through invasive surgical approaches with considerable associated morbidities; improvements in terms of both neurological outcome and extent of resection are the results of the continuous refinement of neurosurgical techniques ${ }^{[12-15]}$. Nowadays, the surgical treatment philosophy for meningiomas is multifaceted, thanks to several adjuvant treatments, i.e., endoscopy, image-guided surgery, neuromonitoring, and radiosurgery. Moreover, recent developments of molecular biology have provided new information in terms of prognosis and indications to secondary treatments, thus leading to innovative, appropriate, and targeted adjuvant therapies granting better quality of life ${ }^{[16-19]}$.

Herein, we provide a cogent analysis of modern surgical indications for meningiomas, with special focus on the role of the endoscopic technique and with a glimpse into the continuous improvement of postoperative treatments.

\section{SURGICAL INDICATIONS AND TECHNIQUES}

Because of the benign nature of the vast majority of meningiomas, total removal leads to the most effective cure, and it is claimed as the gold-standard treatment. The impact of the extent of resection on tumor recurrence rates, traditionally categorized by the Simpson grading system, is the rationale behind aggressive surgical strategies for the management of meningiomas ${ }^{[20]}$. However, the tumor often involves surrounding bone, dura, and neurovascular structures so that complete removal is challenging, sometimes risky, or even 
impossible, especially in the attempt of minimizing morbidity related to the traits of the tumors ${ }^{[2,4,7,17,18]}$. Nonetheless, tumor recurrence can occur, even with radical tumor removal and after long time from the primary surgery ${ }^{[21-23]}$. For these reasons, treatment has moved toward more conservative surgical strategies for meningiomas, opting for a maximum allowed resection, minimizing risks for the neurological functional status, followed by strict imaging surveillance and eventual adjuvant therapies. This attitude shift, supported by a conspicuous amount of data demonstrating that tumor recurrence is a function of tumor biology, have questioned the clinical use of the Simpson grading score ${ }^{[24-28]}$. This latter, indeed, has shown a prognostic value not suitable for all meningioma locations, achieving lesser prognostic impact for skull base and spinal meningiomas as compared to convexity tumors. Furthermore, the histological grade has recently been related to the location, and it has been observed that there is evidence of higher-grade meningiomas at hemispheric/convexity locations. This has to be taken into account when considering surgery for those tumors, which might feature favorable prognostic correlation between location and regrowth.

The ideal surgical approach should allow for maximum extent of resection, i.e., tumor mass removal in addition to infiltrated dura and bone, while minimizing the risk of morbidity. The choice of the most appropriate approach greatly depends on the anatomic features of the meningioma, its relationship with critical neurovascular structures, and the site of dural attachment.

Although the role of surgery for meningiomas might appear to be fairly standardized, class I scientific evidence is uncommon and surgical indications are mainly defined by experience-based practice ${ }^{[16]}$ : the surgical management of a meningioma, indeed, should be tailored upon its nature, symptomatology, patients' characteristics, and risk of morbidity. The observational management for asymptomatic, incidentally discovered meningiomas has been validated by many retrospective series and reviews ${ }^{[7]}$, while surgery is the main choice in cases of radiologically confirmed growth or in the presence of clinical symptoms. In the case of elderly patients and when lesions involve eloquent areas or deep and complex regions such as the cavernous sinus, radiotherapy can be considered as first-line treatment according to tumor size and signs ${ }^{[16,29]}$.

Finally, in the case of spinal meningiomas, the negligible benefits of an aggressive surgical strategy that includes a wide removal of the dural attachment - do not seem to outweigh the risk of surgical complications and patients' morbidity, especially for ventrally located meningiomas or with calcified dural $\operatorname{attachment}^{[23,28,30]}$.

Meningioma surgery was revolutionized in the 1960 s by the advent of the use of the operating microscope: the advancement of microsurgical techniques brought terrific improvement in terms of outcomes and definitely opened the era of modern neurosurgery ${ }^{[31-33]}$. A new level of precision in the surgical removal of tumors, particularly skull base meningiomas, was reached and novel surgical routes have been experimented, with emphasis on a deep understanding of anatomy ${ }^{[34,35]}$. Subsequently, further enthusiasm was brought by the advent of the endoscope in the late $1990 \mathrm{~s}^{[36-39]}$. The intrinsic optical properties of the endoscope, allowing for a wide and close-up view of the surgical field, added extra value to the safety of meningiomas surgical treatment, either as unique visualization tool or as an adjunct to the microscope.

The evolution of the surgical techniques and visualization tools moved along together with instrument development and technological advancements. From the bayonet-shaped instruments used for microsurgical approaches where the lens of the microscope is far from the surgical field, the endoscopic technique requires straight instruments that slide along the endoscope, whose lens is near the surgical target ${ }^{[40,41]}$. Today's visualization tools are upgraded with sophisticated imaging technologies that enhance the capabilities to better identify the tumor-vessels interface, such as infrared technology, 
with administration of intraoperative indocyanine green videoangiography. In meningiomas surgery, this intraoperative tool finds special application in parasagittal tumors ${ }^{[42,43]}$. Maximal safe resection of parasagittal meningiomas is the goal of correct surgical treatment, and it is intimately related to the venous anatomy both near and directly involved by the tumor. Intraoperative indocyanine green videoangiography enables confirming sinus occlusion, removing the occluded portion of the sinus, and identifying and respecting the venous collateral circle.

Finally, in selected cases and alternative to the microscope, meningiomas removal can be performed under exoscope image guidance ${ }^{[44]}$.

\section{Endoscope-assisted surgery}

With increasing experience in skull base surgery, the concept of minimally invasive keyhole approaches flourished, intended not only as limited cranial opening but also as limited approach-associated surgical morbidity, achieved with less traumatism over the brain ${ }^{[45]}$. The supraorbital route and a series of its modifications (the supraorbital eyebrow incision approach, the mini-supraorbital keyhole craniotomy, the transciliary approach, and the lateral supraorbital approach) epitomized the reconciliation of both concepts, benefiting from the tenets of minimal, efficacious access of keyhole approaches and those of maximal, effective, atraumatic brain exposures from skull base ${ }^{[46-48]}$.

The central difficulty of transcranial microsurgical keyhole approaches is the loss of intraoperative light and angle of view due to the limited craniotomy and the need of brain retraction. Continuous improvements in surgical visualization tools' technology led to modern endoscopy and neurosurgeons began using the endoscope as an allied adjunct to the microscope, for the purpose of bringing light and controlling manipulation in the depth of the operating field. Besides, the endoscope's assistance provides extended viewing angle and clear depiction of details in close-up view ${ }^{[49]}$.

The combined microscopic-endoscopic technique has demonstrated utility in two aspects of meningiomas skull base surgery: extension of the surgical field into additional intracranial compartments and visualization and resection of residual tumor not adequately visualized by the microscope around neurovascular corners. In particular, the endoscope allows the extension of posterior cranial approaches to the middle fossa through the tentorial incisura, increasing the resectability of Meckel's cave and petroclival meningiomas that often show a multi-compartment location, involving cavernous sinus, prepontine space, cerebellopontine angle, and lower clivus ${ }^{[50-52]}$. During removal of such meningiomas, the endoscope enables tumor visualization at specific microscopic blind spots: the anterolateral surface of the brainstem, the entrance of the trigeminal nerve into the porous of Meckel's cave and of the VII-VIII cranial nerves into the internal acoustic meatus, and the jugular tubercle with the dural exit of the lower cranial nerves (IX$\mathrm{XI})^{[53,54]}$. Thermal injury to neurovascular structures with the tip of the endoscope should also be taken into account ${ }^{[51]}$. For the removal of anterior skull base meningiomas, the endoscope's assistance finds its main application when combined with the supraorbital approach ${ }^{[51,55,56]}$. The endoscopic visualization discloses surgical corridors to reach the tumor that extends superior, lateral, and under the ipsilateral optic nerve and internal carotid artery, as well as the diaphragm sellae, without the need of splitting the Sylvian fissure. Endoscopic assistance increases the visualization of tumor parts within the olfactory groove that is otherwise limited by the orbital roof under the flat angle of view, as provided by the microscope.

Controversies remain about appropriate case selection, particularly with respect to the extended endoscopic endonasal approaches ${ }^{[57-61]}$ : the supraorbital route can be preferred for meningiomas with significant lateral extension, encroaching the supraclinoid internal carotid artery and its branches and/or extending laterally to the optic nerves that are outside the visibility and maneuverability of the endoscopic endonasal approach. Another criterion to choose the supraorbital approach is the preservation of olfaction that is 
inevitably lost during endoscopic endonasal approaches to the cribriform plate. It is worth mentioning that patients harboring olfactory groove meningiomas frequently present with significant hyposmia and/ or invasion of the lamina cribra and roof of nasal fossae: in these cases, the endonasal approach should be considered as a choice for surgical treatment. In patients with a subchiasmatic lesion and a prefixed chiasm, the endonasal approach is the preferred route because any transcranial approach would require retraction of the optic apparatus with the risk of visual decline.

Endoscope's assistance also finds application in convexity meningiomas located in critical areas. Rolandic and parasagittal meningiomas should be classified as higher risk tumors, as compared to other convexity meningiomas that are associated with low surgical complication rates ${ }^{[2,4,62,63]}$. Even if maximal radicality has to be attempted because of a proven higher recurrence rate after partial resection, the more important goal is not to harm neurological functions. Radical resection may cause severe neurological impairment because of direct mechanical trauma to the eloquent areas, especially if the tumor is tightly adhering to the cortex and/or because of vascular arterial and venous impairment. The close-up view provided by the endoscope may be helpful in the identification of the arachnoid plane at the tumor-cortex and tumorvessels interfaces and can contribute, together with the more established role of electrophysiological mapping and intraoperative videoangiography, to pushing the boundaries of the maximal safe resection in both achieving the best functional results and reducing the tumor remnant volume ${ }^{[42,63]}$.

Lastly, endoscopic spine surgery as an alternative to various open neurosurgical techniques gained popularity in the management of degenerative disc diseases, while its application in treating spinal meningiomas and other intradural lesions remains rather sparse ${ }^{[64,65]}$. The surgical procedure includes access to the spine using tubular ports, parallel or expandable depending on the size of the lesion, thus obviating the need of long skin incisions, paraspinal muscle dissection, and destabilizing dissection of ligamentous structures. Tumor resection is achieved through small bony fenestration under endoscope-assisted microscopic visualization, with occasionally reported pure endoscopic surgical procedures. The benefits of the endoscope become particularly evident in the removal of intradural tumors located anterolaterally to the spinal cord. The endoscope can obviate the use of much more complex anterior routes to the spine, often associated with postoperative spinal deformity and the need for adjunctive fusion surgery, allowing for visualization and removal of the ventrally located part of the tumor, with minimal retraction of the spinal cord. Endoscopic surgery may result equally effective in terms of extent of resection and with similar morbidity compared to open techniques ${ }^{[30,66]}$. The safety of spinal meningiomas removal is increased by the use of intraoperative neuromonitoring that enables the continuous evaluation of the sensory and motor functions of the spinal cord by means of somatosensory-evoked potentials, motor evoked potentials, and $\mathrm{D}$-waves ${ }^{[66]}$. Therefore, intraoperative neuromonitoring should be considered as part of spinal meningiomas surgery, regardless of the surgical approach.

\section{Endoscopic endonasal surgery}

Since the 1990s, continued improvements in illumination and magnification have led to the purely endoscopic transsphenoidal approach to the sella, a development that has subsequently revolutionized the treatment of lesions accessible through the skull base ${ }^{[42,43,67]}$. The introduction of extended endoscopic approaches, technological advancements as well as improvements in skull base reconstruction techniques, and increased experience have established the endoscopic endonasal approach as an important option for anterior skull base meningiomas ${ }^{[68-73]}$. With further expansion of indications, in very selected cases, this approach has entered into the broad spectrum of surgical options for cavernous sinus, petrous ridge, and anterior foramen magnum meningiomas ${ }^{[74-76]}$.

The endonasal approach for anterior skull base meningiomas has several advantages and special anatomic considerations to be underlined ${ }^{[69,71,77-81]}$. Aside from the cosmetic benefit of avoiding external scars, the 
endonasal corridor is a direct path to the tumor, avoiding the need for brain retraction and reducing the manipulation of neurovascular structures on the way to skull base. As part of the approach, an extensive bony and dural resection is achieved and the major vascular supply to the meningioma is addressed before the tumor excision. The main advantage of this surgical route is related to the possibility of achieving an early decompression of the optic apparatus that seems to be associated with more favorable visual outcomes. This is particularly true for tuberculum sellae meningiomas that usually present with visual disturbance because of the intimate anatomical relation between the tumor and the optic apparatus. The endoscopic endonasal technique allows for reduced manipulation of the compressed optic chiasm, and an improved visualization and preservation of perforating vessels. In addition, it provides direct exposure of the inferomedial aspect of the optic canals, allowing for quick decompression in cases of tumor extending within. The main drawback remains the skull base reconstruction, whose failure results in cerebrospinal fluid leakage and its related complications. In recent years, skull base repairing techniques including fat grafts, synthetic materials, and vascular flaps (e.g., the pedicled nasal-septal flap) continue to improve, expanding the indications for these approaches ${ }^{[82-84]}$.

Patient selection is critical for the success of an endoscopic endonasal approach. The question of which tuberculum sellae meningioma should be resected transcranially and which should be approached transsphenoidally remains paramount. Several series have compared approaches and attempted to define which patients are best suited for each approach ${ }^{[61,68,85-89]}$. Larger tumors $(>3 \mathrm{~cm})$ usually extend into multiple areas, making complete removal through the transsphenoidal route challenging. Similarly, tumors with encasement of the carotid arteries and/or anterior communicating artery complex, in the absence of arachnoid plane between the tumor and the surrounding encased vessels, predicts more difficult resection and may limit the efficacy of the endoscopic endonasal approach. The degree of tumor invasion into the optic canal can be a relevant item when choosing the surgical route: whether invasion of the medial inferior and superomedial aspects is present, transsphenoidal approach can be an option, but, if extensive circumferential invasion is present, a craniotomy approach might be necessary. The role of the endoscopic endonasal approach in the treatment of olfactory groove meningiomas is much more controversial and it is still a matter of discussion in the current literature ${ }^{[6,95,90-92]}$. In patients with adequate preoperative olfaction, the endonasal should be not preferred; conversely, the endoscopic approach offers supplementary value for staged or combined procedures in the surgical management of giant olfactory groove meningiomas with significant extension into the nasal cavities and paranasal sinuses.

Finally, advancements in endoscopy have further extended the possibilities of moving to regions outside the nasal sinuses, namely the orbit and the spheno-orbital area. The endoscopic superior eyelid transorbital corridor has recently been explored as a feasible route to address selected lesions at lateral middle fossa and superolateral orbital region, with limited intracranial extension ${ }^{[3-96]}$. In meningiomas surgery, this approach finds its main application in en plaque spheno-orbital tumors. Resection of en plaque meningiomas of the skull base through transcranial approaches can cause significant morbidity, and complete removal is often unattainable. The endoscopic transorbital approach has proven to be effective in greater sphenoidal wing's hyperostosis debulking, which is usually responsible for patient's proptosis, oculomotor, and visual impairment, due to optic canal, superior orbital fissure, and orbital compression. In these cases, clinical benefit is the goal of surgery, rather than complete tumor removal. Extent of resection and symptoms relief can be implemented by the combination with the endonasal transphenoidal approach, which allows for drilling of the medial optic canal and lamina papyracea removal. Further studies with longer followup are needed for a better definition of the pros and cons of this approach compared to more traditional transcranial ones.

\section{ADVANCES IN POSTOPERATIVE TREATMENTS}

In the contemporary era, surgery remains the cornerstone of treatment for meningiomas. At the same time, advances in imaging, treatment planning, and radiation delivery techniques have dramatically 
changed irradiation of these tumors and fractionated radiotherapy and radiosurgery have entered the armamentarium of modern neurosurgery. Advances in the molecular characterization of meningioma have enabled the identification of genetic alterations and methylation profiling subclasses that correlate with the likelihood of tumor recurrence and represent promising medical therapy targets ${ }^{[97,98]}$. Thus, genomics has altered the understanding of the molecular underpinnings of meningiomas, and ongoing clinical trials have the potential to alter how meningiomas are treated.

The high local control rates with low morbidity achieved by radiation modalities and the surgical philosophy of maximal safe resection for meningiomas associated at higher risk of morbidity should guide the best treatment options in a patient-based and lesion-specific approach. Radiotherapy is currently adopted as first-line treatment for cavernous sinus meningiomas, due to increased complication and mortality rates associated to surgical resection ${ }^{[16,29]}$. For adjuvant radiotherapy, the goal of treatment is preventing progression to higher-grade malignancy and decreasing recurrence rate. In cases of grade II (atypical) and grade III (anaplastic/malignant) meningiomas, there is a substantially greater risk of recurrence and a clearer role for adjuvant radiotherapy, even following a gross total resection. It is important to note that recommendations for radiotherapy in different meningioma scenarios, coming from the European Association of Neuro-Oncology (EANO) and the Current National Comprehensive Cancer Network (NCCN), do not take into account tumor location or any molecular pathological markers, and both were published prior to the revised 2016 WHO classification, whose criteria may result in more WHO grade II meningiomas that would have been classified as grade I under the older criteria ${ }^{[16,99]}$.

\section{CONCLUSION}

The continuous evolution of the surgical techniques and, above all, the magnification of the surgical view provided by the endoscope have brought terrific contributions to the effectiveness of meningioma surgery. The most challenging task confronting modern meningioma surgery remains the selection of the most appropriate surgical approach: multiple factors including tumor size consistency and location, extent of dural attachment, and relation with neurovascular structures, along with surgeon's preference and experience, should be taken in account. With the amount of support and guidance that current technologies and advances have provided, modern criteria for meningioma treatment should further consider the careful balance between the desired goal of meningioma surgical cure, and the patient's neurological function preservation should guide the surgery. Improvements in radiation therapy modalities and advances in the molecular characterization of these tumors will further refine the criteria for the surgical approach to meningiomas.

\section{DECLARATIONS}

\section{Authors' contributions}

Made substantial contribution to conception of the study: Cappabianca P, Solari D

Prepared the manuscript draft: d'Avella E

Critically revised the final version of the manuscript: Cappabianca P, Cavallo LM

\section{Availability of data and materials}

Not applicable.

\section{Financial support and sponsorship}

None.

\section{Conflicts of interest}

All authors declared that there are no conflicts of interest. 


\section{Ethical approval and consent to participate}

Not applicable.

\section{Consent for publication}

Not applicable.

\section{Copyright}

(c) The Author(s) 2020.

\section{REFERENCES}

1. DeMonte F, McDermott M, Al-Mefty O. Al-Mefty’s meningiomas. 2th ed. New York: Thieme Medical Publishers; 2011.

2. Lee JH. Meningiomas: diagnosis, treatement and outcome. London: Springer-Verlag; 2009.

3. Wiemels J, Wrensch M, Claus EB. Epidemiology and etiology of meningioma. J Neurooncol 2010;99:307-14.

4. Rogers L, Barani I, Chamberlain M, et al. Meningiomas: knowledge base, treatment outcomes, and uncertainties. A RANO review. $J$ Neurosurg 2015;122:4-23.

5. Louis DN, Perry A, Reifenberger G, et al. The 2016 World Health Organization Classification of Tumors of the Central Nervous System: a summary. Acta Neuropathol 2016;131:803-20.

6. Cushing H, Eisenhardt L. Meningiomas, their classification, regional behaviour, life history, and surgical end results. New York: Hafner; 1938.

7. Islim AI, Mohan M, Moon RDC, et al. Incidental intracranial meningiomas: a systematic review and meta-analysis of prognostic factors and outcomes. J Neurooncol 2019;142:211-21.

8. Watts J, Box G, Galvin A, et al. Magnetic resonance imaging of meningiomas: a pictorial review. Insights Imaging 2014;5:113-22.

9. Tamrazi B, Shiroishi MS, Liu CS. Advanced imaging of intracranial meningiomas. Neurosurg Clin N Am 2016;27:137-43.

10. Hamerla G, Meyer HJ, Schob S, et al. Comparison of machine learning classifiers for differentiation of grade 1 from higher gradings in meningioma: a multicenter radiomics study. Magn Reson Imaging 2019;63:244-9.

11. Zhu Y, Man C, Gong L, et al. A deep learning radiomics model for preoperative grading in meningioma. Eur J Radiol 2019;116:128-34.

12. Yasargil MG. Interfascial pterional (frontotemporosphenoidal) craniotomy. In: Yasargil MG editor. Microneurosurgery. Volume1. Stuttgart: George Thieme Verlag; 1984. pp. 215-20.

13. Jane JA, Park TS, Pobereskin LH, Winn HR, Butler AB. The supraorbital approach: technical note. Neurosurgery 1982;11:537-42.

14. da Costa MDS, Hardesty DA, Priddy B, et al. Extended supraorbital approach with modified eyebrow incision: technical note. World Neurosurg 2019;128:354-9.

15. de Divitiis E, Cavallo LM, Esposito F, Stella L, Messina A. Extended endoscopic transsphenoidal approach for tuberculum sellae meningiomas. Neurosurgery 2007;61:229-37; discussion 237-8.

16. Goldbrunner R, Minniti G, Preusser M, et al. EANO guidelines for the diagnosis and treatment of meningiomas. Lancet Oncol 2016;17:e383-91.

17. Zada G, Jensen RL. Meningiomas: an update on diagnostic and therapeutic approaches. Neurosurg Clin N Am 2016;27:xiii.

18. Cappabianca P, Solari D. Meningiomas of the skull base: treatment nuances in contemporary neurosurgery. New York: Thieme Medical Publishers; 2018.

19. Rockhill J, Mrugala M, Chamberlain MC. Intracranial meningiomas: an overview of diagnosis and treatment. Neurosurg Focus 2007;23:E1.

20. SIMPSON D. The recurrence of intracranial meningiomas after surgical treatment. J Neurol Neurosurg Psychiatry 1957;20:22-39.

21. Gousias K, Schramm J, Simon M. The Simpson grading revisited: aggressive surgery and its place in modern meningioma management. J Neurosurg 2016;125:551-60.

22. Sughrue ME, Kane AJ, Shangari G, et al. The relevance of simpson grade I and II resection in modern neurosurgical treatment of World Health Organization Grade I meningiomas. J Neurosurg 2010;113:1029-35.

23. Barber SM, Konakondla S, Nakhla J, et al. Oncologic benefits of dural resection in spinal meningiomas: a meta-analysis of Simpson grades and recurrence rates. J Neurosurg Spine 2019;1-11.

24. Nanda A, Bir SC, Maiti TK, et al. Relevance of Simpson grading system and recurrence-free survival after surgery for World Health Organization Grade I meningioma. J Neurosurg 2017;126:201-11.

25. Meling TR, Da Broi M, Scheie D, Helseth E. Meningiomas: skull base versus non-skull base. Neurosurg Rev 2019;42:163-73.

26. Voß KM, Spille DC, Sauerland C, et al. The Simpson grading in meningioma surgery: does the tumor location influence the prognostic value? J Neurooncol 2017;133:641-51.

27. Savardekar AR, Patra DP, Bir S, et al. Differential tumor progression patterns in skull base versus non-skull base meningiomas: a critical analysis from a long-term follow-up study and review of literature. World Neurosurg 2018;112:e74-83.

28. Voldřich R, Netuka D, Beneš V. Spinal meningiomas: is Simpson grade II resection radical enough? Acta Neurochir (Wien) 2020;162:1401-8.

29. Pollock BE, Stafford SL. Results of stereotactic radiosurgery for patients with imaging defined cavernous sinus meningiomas. Int $J$ Radiat Oncol Biol Phys 2005;62:1427-31. 
30. Setzer M, Vatter H, Marquardt G, Seifert V, Vrionis FD. Management of spinal meningiomas: surgical results and a review of the literature. Neurosurg Focus 2007;23:E14.

31. Al-Mefty O. Meningiomas. New York: Raven Press; 1991.

32. Uluç K, Kujoth GC, Başkaya MK. Operating microscopes: past, present, and future. Neurosurg Focus 2009;27:E4.

33. Kriss TC, Kriss VM. History of the operating microscope: from magnifying glass to microneurosurgery. Neurosurgery 1998;42:899-907; discussion 907-8.

34. Yasargil MG. Microneurosurgery: microsurgical anatomy of the basal cisterns and vessels of the brain. New York: George Thieme Verlag; 1984.

35. Rothon AL. Rhoton cranial anatomy and surgical approaches. Philadelphia: Lippincott Williams \& Wilkins; 2003.

36. Zada G, Liu C, Apuzzo ML. "Through the looking glass": optical physics, issues, and the evolution of neuroendoscopy. World Neurosurg 2013;79:S3-13.

37. Auer LM, Holzer P, Ascher PW, Heppner F. Endoscopic neurosurgery. Acta Neurochir (Wien) 1988;90:1-14.

38. Jho HD, Carrau RL. Endoscopic endonasal transsphenoidal surgery: experience with 50 patients. J Neurosurg 1997;87:44-51.

39. Cappabianca P, Alfieri A, de Divitiis E. Endoscopic endonasal transsphenoidal approach to the sella: towards functional endoscopic pituitary surgery (FEPS). Minim Invasive Neurosurg 1998;41:66-73.

40. Rothon AL. Operative techniques and instrumentation for neurosurgery. In: Rothon AL, editor. Cranial anatomy and surgical approaches. Philadelphia: Lippincott William \& Wilkins; 2003. pp. 907-34.

41. Cappabianca P, Alfieri A, Thermes S, Buonamassa S, de Divitiis E. Instruments for endoscopic endonasal transsphenoidal surgery. Neurosurgery 1999;45:392-5; discussion 395-6.

42. d'Avella E, Volpin F, Manara R, Scienza R, Della Puppa A. Indocyanine green videoangiography (ICGV)-guided surgery of parasagittal meningiomas occluding the superior sagittal sinus (SSS). Acta Neurochir (Wien) 2013;155:415-20.

43. Della Puppa A, d'Avella E, Volpin F, et al. Indocyanine green videoangiography (ICGV) in parasagittal meningiomas surgery. Considerations on veins management and brain function preservation. Acta Neurochir (Wien) 2013;155:1475-6.

44. De Divitiis O, D'avella E, Denaro L, et al. Vitom 3D: preliminary experience with intradural extramedullary spinal tumors. J Neurosurg Sci 2019; doi: 10.23736/S0390-5616.19.04666-6.

45. Perneczky A, Reisch R. Keyhole approaches in neurosurgery: volume 1: concept and surgical technique. Wien: Springer Verlag; 2008.

46. Eroglu U, Shah K, Bozkurt M, et al. Supraorbital keyhole approach: lessons learned from 106 operative cases. World Neurosurg 2019:e667-74.

47. Zumofen DW, Rychen J, Roethlisberger M, et al. A review of the literature on the transciliary supraorbital keyhole approach. World Neurosurg 2017;98:614-24.

48. Romani R, Lehecka M, Gaal E, et al. Lateral supraorbital approach applied to olfactory groove meningiomas: experience with 66 consecutive patients. Neurosurgery 2009;65:39-52; discussion 52-3.

49. Fries G, Perneczky A. Endoscope-assisted brain surgery: part 2--analysis of 380 procedures. Neurosurgery 1998;42:226-31; discussion 231-2.

50. Tomasello F, Angileri FF, Conti A, et al. Petrosal meningiomas: factors affecting outcome and the role of intraoperative multimodal assistance to microsurgery. Neurosurgery 2019;84:1313-24.

51. Schroeder HW, Hickmann AK, Baldauf J. Endoscope-assisted microsurgical resection of skull base meningiomas. Neurosurg Rev 2011;34:441-55.

52. Tatagiba M, Rigante L, Mesquita Filho P, Ebner FH, Roser F. Endoscopic-assisted posterior intradural petrous apicectomy in petroclival meningiomas: a clinical series and assessment of perioperative morbidity. World Neurosurg 2015;84:1708-18.

53. Abolfotoh M, Bi WL, Hong CK, et al. The combined microscopic-endoscopic technique for radical resection of cerebellopontine angle tumors. J Neurosurg 2015;123:1301-11.

54. de Notaris M, Cavallo LM, Prats-Galino A, et al. Endoscopic endonasal transclival approach and retrosigmoid approach to the clival and petroclival regions. Neurosurgery 2009;65:42-50; discussion 50-2.

55. Wilson DA, Duong H, Teo C, Kelly DF. The supraorbital endoscopic approach for tumors. World Neurosurg 2014;82:S72-80.

56. Berhouma M, Jacquesson T, Jouanneau E. The fully endoscopic supraorbital trans-eyebrow keyhole approach to the anterior and middle skull base. Acta Neurochir (Wien) 2011;153:1949-54.

57. Fatemi N, Dusick JR, de Paiva Neto MA, Malkasian D, Kelly DF. Endonasal versus supraorbital keyhole removal of craniopharyngiomas and tuberculum sellae meningiomas. Neurosurgery 2009;64:269-84; discussion 284-6.

58. de Divitiis E, Esposito F, Cappabianca P, Cavallo LM, de Divitiis O. Tuberculum sellae meningiomas: high route or low route? A series of 51 consecutive cases. Neurosurgery 2008;62:556-63; discussion 556-63.

59. Schwartz TH. An eyebrow for an eyebrow and a nose for a nose. World Neurosurg 2014;82:e97-9.

60. Ottenhausen M, Rumalla K, Alalade AF, et al. Decision-making algorithm for minimally invasive approaches to anterior skull base meningiomas. Neurosurg Focus 2018;44:E7.

61. Giammattei L, Starnoni D, Cossu G, et al. Surgical management of tuberculum sellae meningiomas: myths, facts, and controversies. Acta Neurochir (Wien) 2020;162:631-40.

62. Alvernia JE, Dang ND, Sindou MP. Convexity meningiomas: study of recurrence factors with special emphasis on the cleavage plane in a series of 100 consecutive patients. J Neurosurg 2011;115:491-8.

63. Ostrý S, Netuka D, Beneš V. Rolandic area meningioma resection controlled and guided by intraoperative cortical mapping. Acta Neurochir (Wien) 2012;154:843-53. 
64. Parihar VS, Yadav N, Yadav YR, et al. Endoscopic Management of spinal intradural extramedullary tumors. J Neurol Surg A Cent Eur Neurosurg 2017;78:219-26.

65. Dhandapani S, Karthigeyan M. "Microendoscopic" versus "pure endoscopic" surgery for spinal intradural mass lesions: a comparative study and review. Spine J 2018;18:1592-602.

66. Hohenberger C, Gugg C, Schmidt NO, Zeman F, Schebesch KM. Functional outcome after surgical treatment of spinal meningioma. $J$ Clin Neurosci 2020;77:62-6.

67. Cappabianca P, Cavallo LM, Esposito F, et al. Extended endoscopic endonasal approach to the midline skull base: the evolving role of transsphenoidal surgery. In: Pickard JD, Akalan N, Di Rocco C, Dolenc VV, Antunes JL, Mooij JJA, Schramm J, Sindou M, editors. Advances and Technical Standards in Neurosurgery. Vienna: Springer; 2008. pp. 151-99.

68. de Divitiis E, Esposito F, Cappabianca P, et al. Endoscopic transnasal resection of anterior cranial fossa meningiomas. Neurosurg Focus 2008;25:E8.

69. Cavallo LM, Messina A, Cappabianca P, et al. Endoscopic endonasal surgery of the midline skull base: anatomical study and clinical considerations. Neurosurg Focus 2005;19:E2.

70. Jane JA Jr, Dumont AS, Vance ML, Laws ER Jr. The transsphenoidal transtuberculum sellae approach for suprasellar meningiomas. Seminars Neurosurg 2003;14:211-8.

71. Kassam A, Snyderman CH, Mintz A, Gardner P, Carrau RL. Expanded endonasal approach: the rostrocaudal axis. Part I. Crista galli to the sella turcica. Neurosurg Focus 2005;19:E3.

72. Laufer I, Anand VK, Schwartz TH. Endoscopic, endonasal extended transsphenoidal, transplanum transtuberculum approach for resection of suprasellar lesions. J Neurosurg 2007;106:400-6.

73. Ditzel Filho LF, Prevedello DM, Jamshidi AO, et al. Endoscopic endonasal approach for removal of tuberculum sellae meningiomas. Neurosurg Clin N Am 2015;26:349-61.

74. Koutourousiou M, Fernandez-Miranda JC, Vaz-Guimaraes Filho F, et al. Outcomes of endonasal and lateral approaches to petroclival meningiomas. World Neurosurg 2017;99:500-17.

75. Lobo B, Zhang X, Barkhoudarian G, Griffiths CF, Kelly DF. Endonasal endoscopic management of parasellar and cavernous sinus meningiomas. Neurosurg Clin N Am 2015;26:389-401.

76. Beer-Furlan A, Abi-Hachem R, Jamshidi AO, Carrau RL, Prevedello DM. Endoscopic trans-sphenoidal surgery for petroclival and clival meningiomas. J Neurosurg Sci 2016;60:495-502.

77. Cavallo LM, de Divitiis O, Aydin S, et al. Extended endoscopic endonasal transsphenoidal approach to the suprasellar area: anatomic considerations--part 1. Neurosurgery 2007;61:24-33; discussion 33-4.

78. Cappabianca P, Frank G, Pasquini E, de Divitiis O, Calbucci F. Extended endoscopic endonasal transsphenoidal approaches to the suprasellar region, planum sphenoidale and clivus. In: Cappabianca P, de Divitiis E, editors. Endoscopic Endonasal Transsphenoidal Surgery. Wien: Springer-Verlag; 2003. pp. 176-87.

79. Koutourousiou M, Fernandez-Miranda JC, Stefko ST, et al. Endoscopic endonasal surgery for suprasellar meningiomas: experience with 75 patients. J Neurosurg 2014;120:1326-39.

80. Gardner PA, Kassam AB, Thomas A, et al. Endoscopic endonasal resection of anterior cranial base meningiomas. Neurosurgery 2008;63:36-52; discussion 52-4.

81. Cavallo LM, Andaluza N, Di Somma A, Solari D, Cappabianca P. Tuberculum sellae/planum meningiomas. In: Cappabianca P, Solari D, editors. Meningiomas of the skull base: treatment nuances in contemporary neurosurgery. New York: Thieme Medical Publishers; 2019. pp. 127-37.

82. Hadad G, Bassagasteguy L, Carrau RL, et al. A novel reconstructive technique after endoscopic expanded endonasal approaches: vascular pedicle nasoseptal flap. Laryngoscope 2006;116:1882-6.

83. Esposito F, Dusick JR, Fatemi N, Kelly DF. Graded repair of cranial base defects and cerebrospinal fluid leaks in transsphenoidal surgery. Oper Neurosurg (Hagerstown) 2007;60:295-303; discussion 303-4.

84. Cavallo LM, Solari D, Somma T, Cappabianca P. The 3F (Fat, Flap, and Flash) Technique for skull base reconstruction after endoscopic endonasal suprasellar approach. World Neurosurg 2019;126:439-46.

85. Komotar RJ, Starke RM, Raper DM, Anand VK, Schwartz TH. Endoscopic endonasal versus open transcranial resection of anterior midline skull base meningiomas. World Neurosurg 2012;77:713-24.

86. Magill ST, Morshed RA, Lucas CG, et al. Tuberculum sellae meningiomas: grading scale to assess surgical outcomes using the transcranial versus transsphenoidal approach. Neurosurg Focus 2018;44:E9.

87. Cappabianca P, Esposito F, Solari D. Endoscopic removal of tuberculum sellae meningiomas. In: Al-Mefty O, editor. Controversies in Neurosurgery II. New York: Thieme; 2013. pp. 234-48.

88. Mariniello G, de Divitiis O, Bonavolontà G, Maiuri F. Surgical unroofing of the optic canal and visual outcome in basal meningiomas. Acta Neurochir (Wien) 2013;155:77-84.

89. Mahmoud M, Nader R, Al-Mefty O. Optic canal involvement in tuberculum sellae meningiomas: influence on approach, recurrence, and visual recovery. Neurosurgery 2010;67:ons108-18; discussion ons118-9.

90. Purohit A, Jha R, Khalafallah AM, et al. Endoscopic endonasal versus transcranial approach to resection of olfactory groove meningiomas: a systematic review. Neurosurg Rev 2019; doi: 10.1007/s10143-019-01193-2

91. Koutourousiou M, Fernandez-Miranda JC, Wang EW, Snyderman CH, Gardner PA. Endoscopic endonasal surgery for olfactory groove meningiomas: outcomes and limitations in 50 patients. Neurosurg Focus 2014;37:E8.

92. de Divitiis E, Cavallo LM, Cappabianca P, Esposito F. Extended endoscopic endonasal transsphenoidal approach for the removal of 
suprasellar tumors: Part 2. Neurosurgery 2007;60:46-58; discussion 58-9.

93. Dallan I, Sellari-Franceschini S, Turri-Zanoni M, et al. Endoscopic transorbital superior eyelid approach for the management of selected spheno-orbital meningiomas: preliminary experience. Oper Neurosurg (Hagerstown) 2018;14:243-51.

94. Almeida JP, Omay SB, Shetty SR, et al. Transorbital endoscopic eyelid approach for resection of sphenoorbital meningiomas with predominant hyperostosis: report of 2 cases. J Neurosurg 2018;128:1885-95.

95. De Rosa A, Pineda J, Cavallo LM, et al. Endoscopic endo- and extra-orbital corridors for spheno-orbital region: anatomic study with illustrative case. Acta Neurochir (Wien) 2019;161:1633-46.

96. Di Somma A, Andaluz N, Cavallo LM, et al. Endoscopic transorbital superior eyelid approach: anatomical study from a neurosurgical perspective. J Neurosurg 2018;129:1203-16.

97. Proctor DT, Ramachandran S, Lama S, Sutherland GR. Towards molecular classification of meningioma: evolving treatment and diagnostic paradigms. World Neurosurg 2018;119:366-73.

98. Pereira BJA, Oba-Shinjo SM, de Almeida AN, Marie SKN. Molecular alterations in meningiomas: Literature review. Clin Neurol Neurosurg 2019;176:89-96.

99. Nabors LB, Portnow J, Ammirati M, et al. Central nervous system cancers, version 1.2015. J Natl Compr Canc Netw 2015;13:1191-202. 